\title{
A Note on Some Best Proximity Point Theorems Proved under $P$-Property
}

\author{
Ali Abkar' and Moosa Gabeleh ${ }^{2}$ \\ ${ }^{1}$ Department of Mathematics, Imam Khomeini International University, Qazvin 34149, Iran \\ ${ }^{2}$ Department of Mathematics, Ayatollah Boroujerdi University, Borujerd, Iran
}

Correspondence should be addressed to Moosa Gabeleh; gab.moo@gmail.com

Received 20 July 2013; Accepted 29 September 2013

Academic Editor: Mohamed Jleli

Copyright (C) 2013 A. Abkar and M. Gabeleh. This is an open access article distributed under the Creative Commons Attribution License, which permits unrestricted use, distribution, and reproduction in any medium, provided the original work is properly cited.

We show that some recent results concerning the existence of best proximity points can be obtained from the same results in fixed point theory.

\section{Introduction}

Let $A$ and $B$ be two nonempty subsets of a metric space $(X, d)$. In this paper, we adopt the following notations and definitions:

$$
\begin{gathered}
D(x, B):=\inf \{d(x, y): y \in B\}, \quad \forall x \in X, \\
A_{0}:=\{x \in A: d(x, y)=\operatorname{dist}(A, B), \text { for some } y \in B\}, \\
B_{0}:=\{y \in B: d(x, y)=\operatorname{dist}(A, B), \text { for some } x \in A\} .
\end{gathered}
$$

The notion of best proximity point is defined as follows.

Definition 1. Let $A$ and $B$ be nonempty subsets of a metric space $(X, d)$ and $T: A \rightarrow B$ a non-self-mapping. A point $x^{*} \in A$ is called a best proximity point of $T$ if $d\left(x^{*}, T x^{*}\right)=$ $\operatorname{dist}(A, B)$, where

$$
\operatorname{dist}(A, B):=\inf \{d(x, y):(x, y) \in A \times B\} .
$$

Similarly, for a multivalued non-self-mapping $T: A \rightarrow$ $2^{B}$, where $(A, B)$ is a nonempty pair of subsets of a metric space $(\mathrm{X}, d)$, a point $x^{*} \in A$ is a best proximity point of $T$ provided that $D\left(x^{*}, T x^{*}\right)=\operatorname{dist}(A, B)$.

Recently, the notion of $P$-property was introduced in [1] as follows.
Definition 2 (see [1]). Let $(A, B)$ be a pair of nonempty subsets of a metric space $(X, d)$ with $A_{0} \neq \emptyset$. The pair $(A, B)$ is said to have $P$-property if and only if

$$
\begin{aligned}
& d\left(x_{1}, y_{1}\right)=\operatorname{dist}(A, B) \\
& d\left(x_{2}, y_{2}\right)=\operatorname{dist}(A, B)
\end{aligned} \Longrightarrow d\left(x_{1}, x_{2}\right)=d\left(y_{1}, y_{2}\right)
$$

where $x_{1}, x_{2} \in A_{0}$ and $y_{1}, y_{2} \in B_{0}$.

By using this notion, some best proximity point results were proved for various classes of non-self-mappings. Here, we state some of them.

Theorem 3 (see [1]). Let $(A, B)$ be a pair of nonempty closed subsets of a complete metric space $X$ such that $A_{0}$ is nonempty. Let $T: A \rightarrow B$ be a weakly contractive non-self-mapping; that is,

$$
d(T x, T y) \leq d(x, y)-\phi(d(x, y)) \quad \forall x, y \in A,
$$

where $\phi:[0, \infty) \rightarrow[0, \infty)$ is a continuous and nondecreasing function such that $\phi$ is positive on $(0, \infty), \phi(0)=0$, and $\lim _{t \rightarrow \infty} \phi(t)=\infty$. Assume that the pair $(A, B)$ has the $P$ property and $T\left(A_{0}\right) \subseteq B_{0}$. Then, $T$ has a unique best proximity point. 
Theorem 4 (see [2]). Let $(A, B)$ be a pair of nonempty closed subsets of a Banach space $X$ such that $A$ is compact and $A_{0}$ is nonempty. Let $T: A \rightarrow B$ be a nonexpansive mapping; that is,

$$
\|T x-T y\| \leq\|x-y\|, \quad \forall x, y \in A .
$$

Assume that the pair $(A, B)$ has the P-property and $T\left(A_{0}\right) \subseteq$ $B_{0}$. Then, $T$ has a best proximity point.

Theorem 5 (see [3]). Let $(A, B)$ be a pair of nonempty closed subsets of a complete metric space $X$ such that $A_{0}$ is nonempty. Let $T: A \rightarrow B$ be a Meir-Keeler non-self-mapping; that is, for all $x, y \in A$ and for any $\varepsilon>0$, there exists $\delta(\varepsilon)>0$ such that

$$
\varepsilon \leq d(x, y)<\varepsilon+\delta \quad \text { implies } d(T x, T y) \leq \varepsilon .
$$

Assume that the pair $(A, B)$ has the P-property and $T\left(A_{0}\right) \subseteq$ $B_{0}$. Then, $T$ has a unique best proximity point.

Theorem 6 (see [4]). Let $(A, B)$ be a pair of nonempty closed subsets of a complete metric space $(X, d)$ such that $A_{0} \neq \emptyset$ and $(A, B)$ satisfies the P-property. Let $T: A \rightarrow 2^{B}$ be a multivalued contraction non-self-mapping; that is,

$$
H(T x, T y) \leq \alpha d(x, y),
$$

for some $\alpha \in(0,1)$ and for all $x, y \in A$. If Tx is bounded and closed in $B$ for all $x \in A$ and T $x_{0}$ is included in $B_{0}$ for each $x_{0} \in A_{0}$, then $T$ has a best proximity point in $A$.

Theorem 7 (see [5]). Let $(A, B)$ be a pair of nonempty closed subsets of a complete metric space $X$ such that $A_{0}$ is nonempty. Let $T: A \rightarrow B$ be a Geraghty-contraction non-self-mapping; that is,

$$
d(T x, T y) \leq \beta(d(x, y)), d(x, y), \quad \forall x, y \in A,
$$

where $\beta:[0, \infty) \rightarrow[0,1)$ is a function which satisfies the following condition:

$$
\beta\left(t_{n}\right) \longrightarrow 1 \Longrightarrow t_{n} \longrightarrow 0
$$

Suppose that the pair $(A, B)$ has the P-property and $T\left(A_{0}\right) \subseteq$ $B_{0}$. Then, $T$ has a unique best proximity point.

\section{Main Result}

In this section, we show that the existence of a best proximity point in the main theorems of [1-5] can be obtained from the existence of the fixed point for a self-map. We begin our argument with the following lemmas.

Lemma 8 (see [6]). Let $(A, B)$ be a pair of nonempty closed subsets of a complete metric space $(X, d)$ such that $A_{0}$ is nonempty and $(A, B)$ has the P-property. Then, $\left(A_{0}, B_{0}\right)$ is a closed pair of subsets of $X$.

Lemma 9. Let $(A, B)$ be a pair of nonempty closed subsets of a metric space $(X, d)$ such that $A_{0}$ is nonempty. Assume that the pair $(A, B)$ has the P-property. Then there exists a bijective isometry $g: A_{0} \rightarrow B_{0}$ such that $d(x, g x)=\operatorname{dist}(A, B)$.
Proof. Let $x \in A_{0}$; then there exists an element $y \in B_{0}$ such that

$$
d(x, y)=\operatorname{dist}(A, B) \text {. }
$$

Assume that there exists another point $y \in B_{0}$ such that

$$
d(x, \hat{y})=\operatorname{dist}(A, B) .
$$

By the fact that $(A, B)$ has the $P$-property, we conclude that $y=y$. Consider the non-self-mapping $g: A_{0} \rightarrow B_{0}$ such that $d(x, g x)=\operatorname{dist}(A, B)$. Clearly, $g$ is well defined. Moreover, $g$ is an isometry. Indeed, if $x_{1}, x_{2} \in A_{0}$, then

$$
d\left(x_{1}, g x_{1}\right)=\operatorname{dist}(A, B), \quad d\left(x_{2}, g x_{2}\right)=\operatorname{dist}(A, B) .
$$

Again, since $(A, B)$ has the $P$-property,

$$
d\left(x_{1}, x_{2}\right)=d\left(g x_{1}, g x_{2}\right)
$$

that is, $g$ is an isometry.

Here, we prove that the existence and uniqueness of the best proximity point in Theorem 3 are a sample result of the existence of fixed point for a weakly contractive self-mapping.

Theorem 10. Let $(A, B)$ be a pair of nonempty closed subsets of a complete metric space $X$ such that $A_{0}$ is nonempty. Let $T: A \rightarrow B$ be a weakly contractive mapping. Assume that the pair $(A, B)$ has the P-property and $T\left(A_{0}\right) \subseteq B_{0}$. Then, $T$ has a unique best proximity point.

Proof. Consider the bijective isometry $g: A_{0} \rightarrow B_{0}$ as in Lemma 9. Since $T\left(A_{0}\right) \subseteq B_{0}$, for the self-mapping $g^{-1} T$ : $A_{0} \rightarrow A_{0}$, we have

$$
d\left(g^{-1}(T x), g^{-1}(T y)\right)=d(T x, T y) \leq \varphi(d(x, y)),
$$

for all $x, y \in A_{0}$ which implies that the self-mapping $g^{-1} T$ is weakly contractive. Note that $A_{0}$ is closed by Lemma 8 . Thus, $g^{-1} T$ has a unique fixed point [7]. Suppose that $x^{*} \in A_{0}$ is a unique fixed point of the self-mapping $g^{-1} T$; that is, $g^{-1} T\left(x^{*}\right)=x^{*}$. So, $T x^{*}=g x^{*}$, and then

$$
d\left(x^{*}, T x^{*}\right)=d\left(x^{*}, g x^{*}\right)=\operatorname{dist}(A, B),
$$

from which it follows that $x^{*} \in A_{0}$ is a unique best proximity point of the non-self weakly contractive mapping $T$.

Remark 11. By a similar argument, using the fact that every nonexpansive self-mapping defined on a nonempty compact and convex subset of a Banach space has a fixed point, we conclude Theorem 4 . Also, the existence and uniqueness of best proximity point for Meir-Keeler non-self-mapping $T$ (Theorem 5) follow from the Meir-Keeler's fixed point theorem ([8]). Moreover, in Theorem 6, Nadler's fixed point theorem ([9]) ensures the existence of a best proximity point for multivalued non-self mapping $T$. Finally, Theorem 7 due to Caballero et al., is obtained from Geraghty's fixed point theorem $([10])$. 


\section{References}

[1] V. S. Raj, "A best proximity point theorem for weakly contractive non-self-mappings," Nonlinear Analysis. Theory, Methods \& Applications, vol. 74, no. 14, pp. 4804-4808, 2011.

[2] A. Abkar and M. Gabeleh, "Best proximity points of non-self mappings," TOP, vol. 21, no. 2, pp. 287-295, 2013.

[3] B. Samet, "Some results on best proximity point theorem," Journal of Optimization Theory and Applications, vol. 159, no. 1, pp. 281-291, 2013.

[4] A. Abkar and M. Gabeleh, "The existence of best proximity points for multivalued non-self-mappings," Revista de la Real Academia de Ciencias Exactas, Fisicas y Naturales A, vol. 107, no. 2, pp. 319-325, 2013.

[5] J. Caballero, J. Harjani, and K. Sadarangani, "A best proximity point theorem for Geraghty-contractions," Fixed Point Theory and Applications, vol. 2012, article 231, 2012.

[6] M. Gabeleh, "Proximal weakly contractive and proximal nonexpansive non-self-mappings in metric and Banach spaces," Journal of Optimization Theory and Applications, vol. 158, no. 2, pp. 615-625, 2013.

[7] B. E. Rhoades, "Some theorems on weakly contractive maps," Nonlinear Analysis, Theory, Methods and Applications, vol. 47, no. 4, pp. 2683-2693, 2001.

[8] A. Meir and E. Keeler, "A theorem on contraction mappings," Journal of Mathematical Analysis and Applications, vol. 28, pp. 326-329, 1969.

[9] S. B. Nadler, Jr., "Multi-valued contraction mappings," Pacific Journal of Mathematics, vol. 30, pp. 475-488, 1969.

[10] M. A. Geraghty, "On contractive mappings," Proceedings of the American Mathematical Society, vol. 40, pp. 604-608, 1973. 


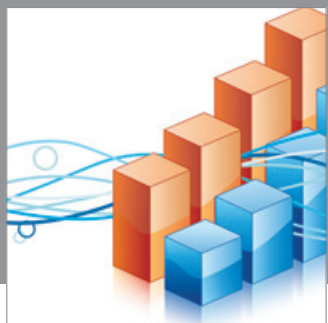

Advances in

Operations Research

mansans

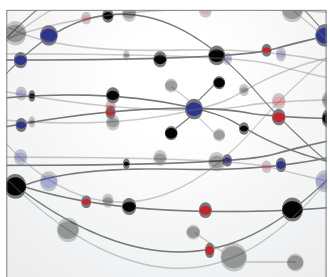

The Scientific World Journal
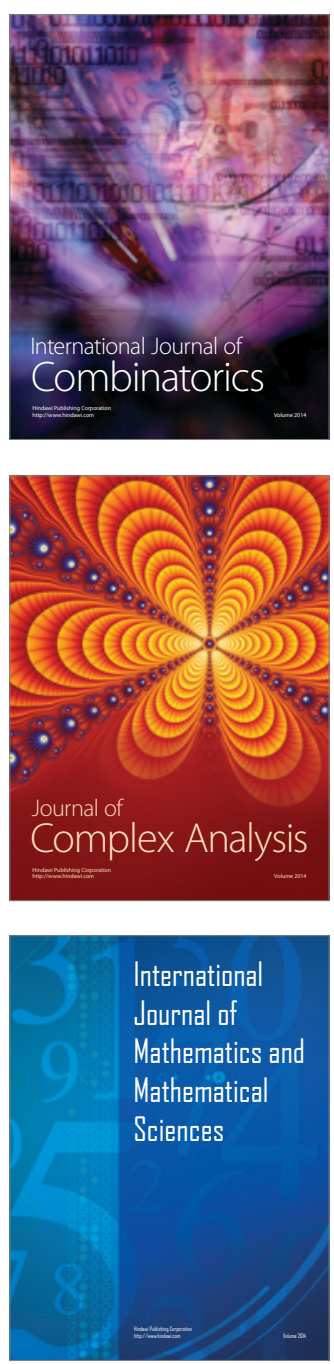
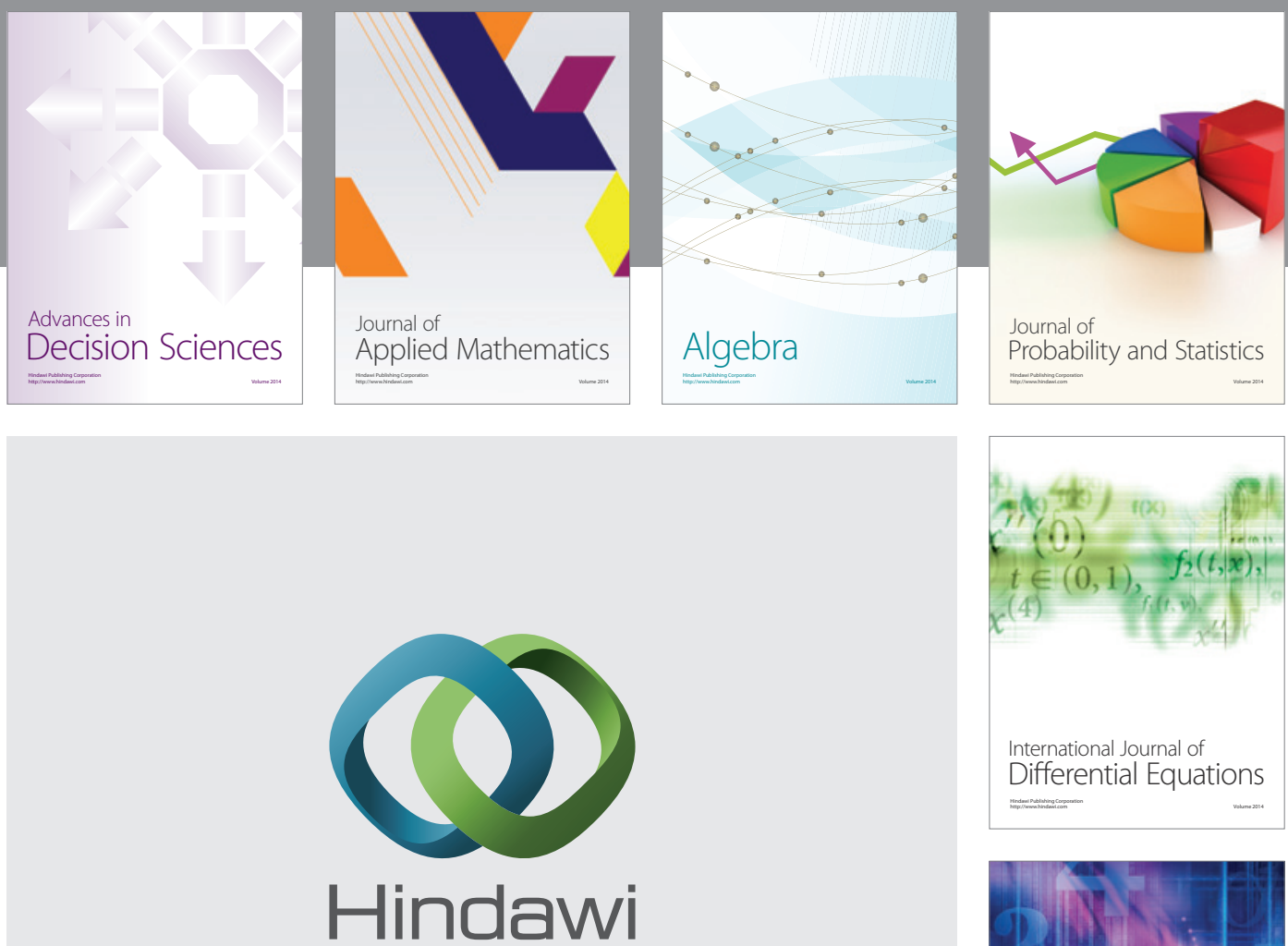

Submit your manuscripts at http://www.hindawi.com
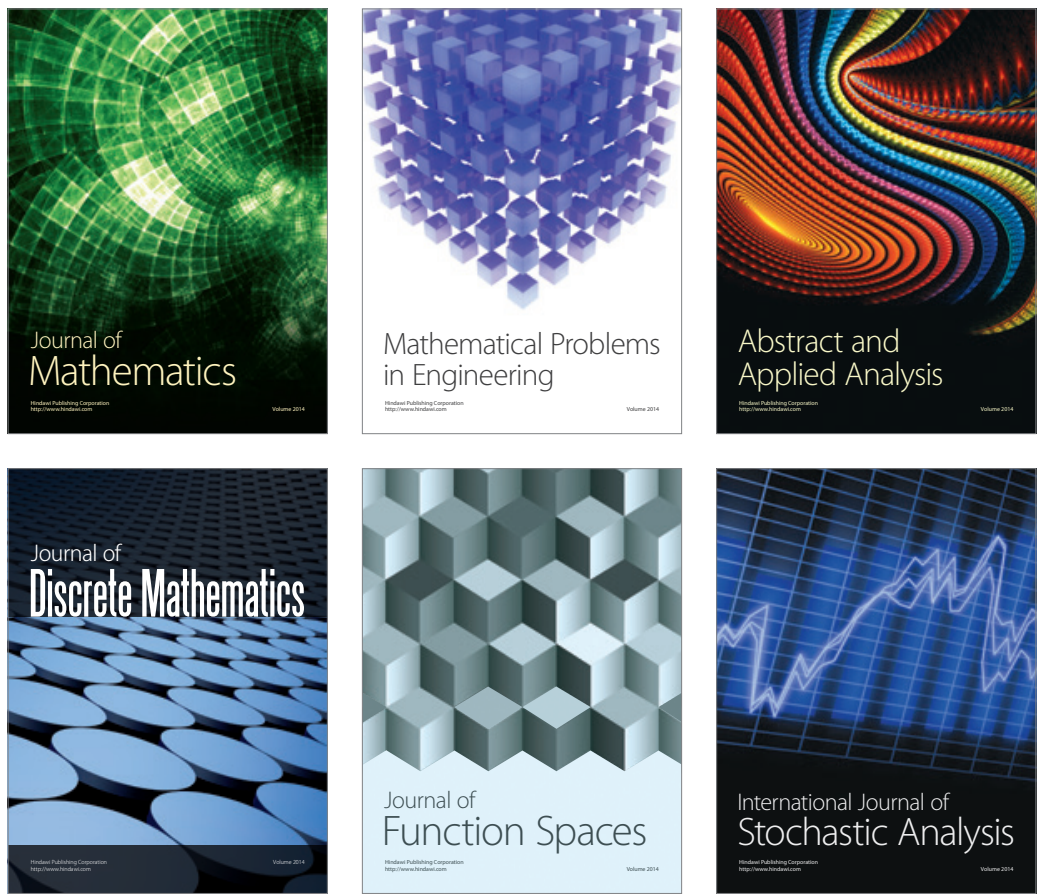

Journal of

Function Spaces

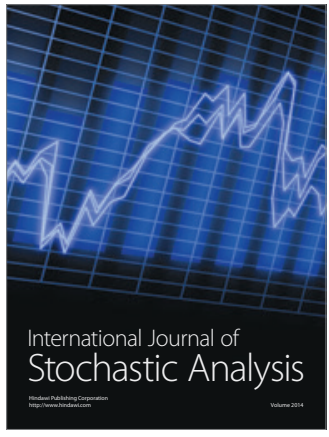

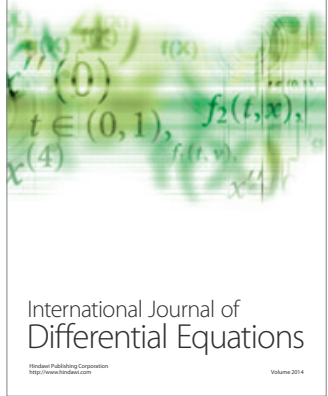
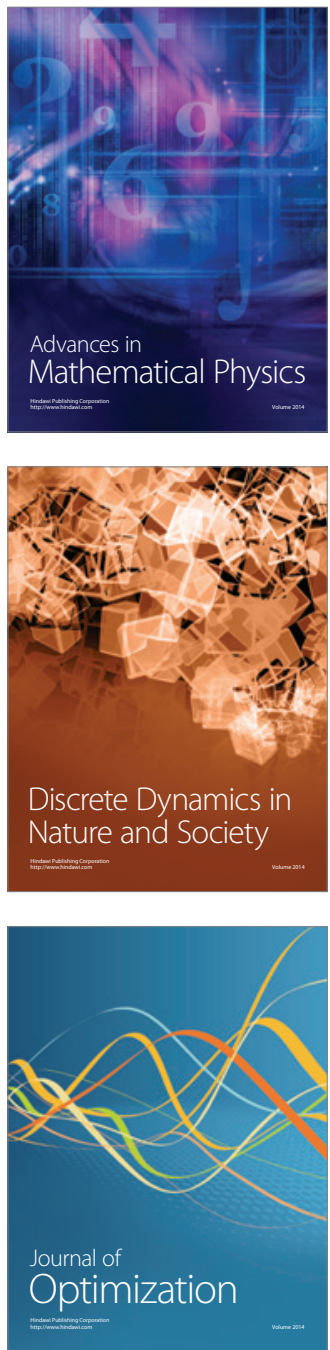